\title{
Participative irrigation management in the Jordan Valley
}

\author{
A. Al Adwan ${ }^{1} \&$ B. O. Hayek ${ }^{2}$ \\ ${ }^{I}$ GTZ German-Jordan Program, Management of Water Resources, \\ Water Users Association Component, Jordan \\ ${ }^{2}$ Department of Environment Management, \\ Princess Sumaya University for Technology, Jordan
}

\begin{abstract}
Retail irrigation water management in the Jordan Valley has been subjected to a comprehensive program for improvement since 2001 aiming at improving the efficiency of water distribution. Participative irrigation management approach was selected as a strategic option. The implementation of the program was launched in 3 pilots (north, middle, and south). The program started by rebuilding trust and advancing mutual understanding between the farmers and the Jordan Valley Authority (JVA) after a few years of disparity. The program also included contributing in reclaiming the network and providing know-how transfer to bring the farmers to an appropriate operational position and cooperative mode. Water users associations (WUAs) were formed where a democratic process was instituted to select the members on duty and the management structure. Contracts were achieved with WUAs that reached tasks transfer; where WUAs became responsible for the distribution of the water for irrigation. Yet to ensure the sustainability of the experience, a bylaw for the WUAs was prepared in cooperation with the farmers, while a federation for WUAs will be reached in the near future.

Farmers reported improved productivity due to availability of water on a regular basis. Illegal use of water was dramatically reduced and a fair water distribution was reached. Today 21 WUAs serve $3 / 4$ of the irrigated land in the Jordan Valley. WUAs and JVA established sort of a partnership for the efficient water use in irrigation by cooperating in retail water management. The step wise
\end{abstract}


approach to participative irrigation while giving due attention to the local circumstances was indeed essential for the success of the program.

Keywords: participative irrigation, water users groups, water users associations, water management in the Jordan valley, efficiency of retail water distribution.

\section{Introduction}

The Jordan Valley (Figure 1) had been known as the fresh fruit and vegetables supplier to Jordan. This status, however, was challenged along the years by the continuous stress on water resources. The municipal, tourism, and industrial water needs were somehow being met on the expense of the water available in

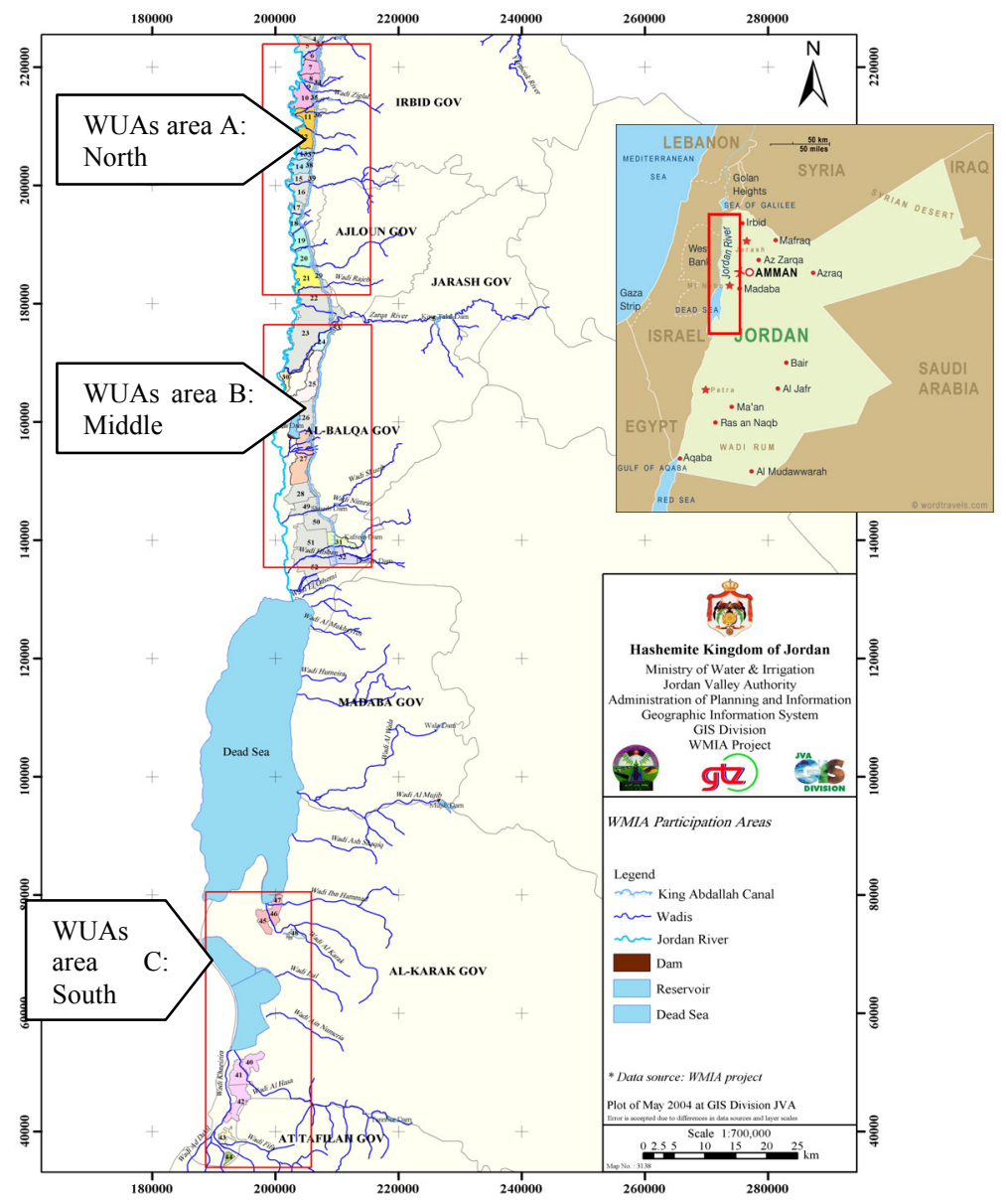

Figure 1: Study area in the Jordan valley and the location of the water users association. 
the valley for agriculture. The Jordan Valley Authority (JVA), established in 1977, was mandated to manage the resources and the socio-economic development of the valley (including its water resources) and the responsibility of water supply and irrigation water distribution for agriculture. JVA showed an excellent model in the management of bulk water, but in the 1990s the retail irrigation water distribution faced a gradual decrease in efficiency due to several factors such as maintenance costs and deterioration of the network. As a result the farmers started to loose faith in the operation and to compete on the water. JVA was gradually overwhelmed with bureaucratic processes and lack of resources to manage the situation. This eventually led to jeopardizing the efficiency of water distribution in the valley and lack of trust between the farmers and the authority [1].

In 2001 following severe droughts and cuts on water for agriculture, JVA called for serious plans to reclaim the situation. JVA in cooperation with the German Jordanian Water Resources Management Program stepped in to introduce a sustainable participatory approach for water resources management in irrigated agriculture with the goal of "efficiency of irrigation in the Jordan Valley is increased". The Jordan Valley Development Law was also amended for the purpose of improving efficiency and cost effectiveness of JVA processes. The amendment gave JVA more focus on water management and distribution among some other duties [2]. The development in the JVA mandate, the initiated project and the need of the farmers to see a good change provided a fertile, though challenging, ground for the participative irrigation management.

\section{Methodology}

A step wise approach was adopted to reach farmers' participation in water distribution management through water users associations (WUAs). Phases of work (Figure 2) and action plans were designed to build awareness on problems and potential solutions, regaining the mutual confidence (between the farmers and JVA and among the farmers themselves), and organizational structure development and technical improvements for the water distribution system.

The indicators were set and upgraded through the implementation according to performance. The final indicators were

- Membership of farmers in WUAs will cover $70 \%$ of all irrigated area in the Jordan Valley;

- Founding documents of a federative organization representing regional interest of water users in Jordan Valley are signed; and

- At least $60 \%$ of members of WUAs are, according to a survey, satisfied with water distribution services.

The concept of managing the irrigation water by the farmers used to be practiced in the past i.e. long before the formation of JVA in 1977. That was the indigenous or traditional practice according to an effective societal traditional control system. This practice was somehow lost by having the water distribution mandated to the authority since 1977. To reinitiate the concept in 2001 and 


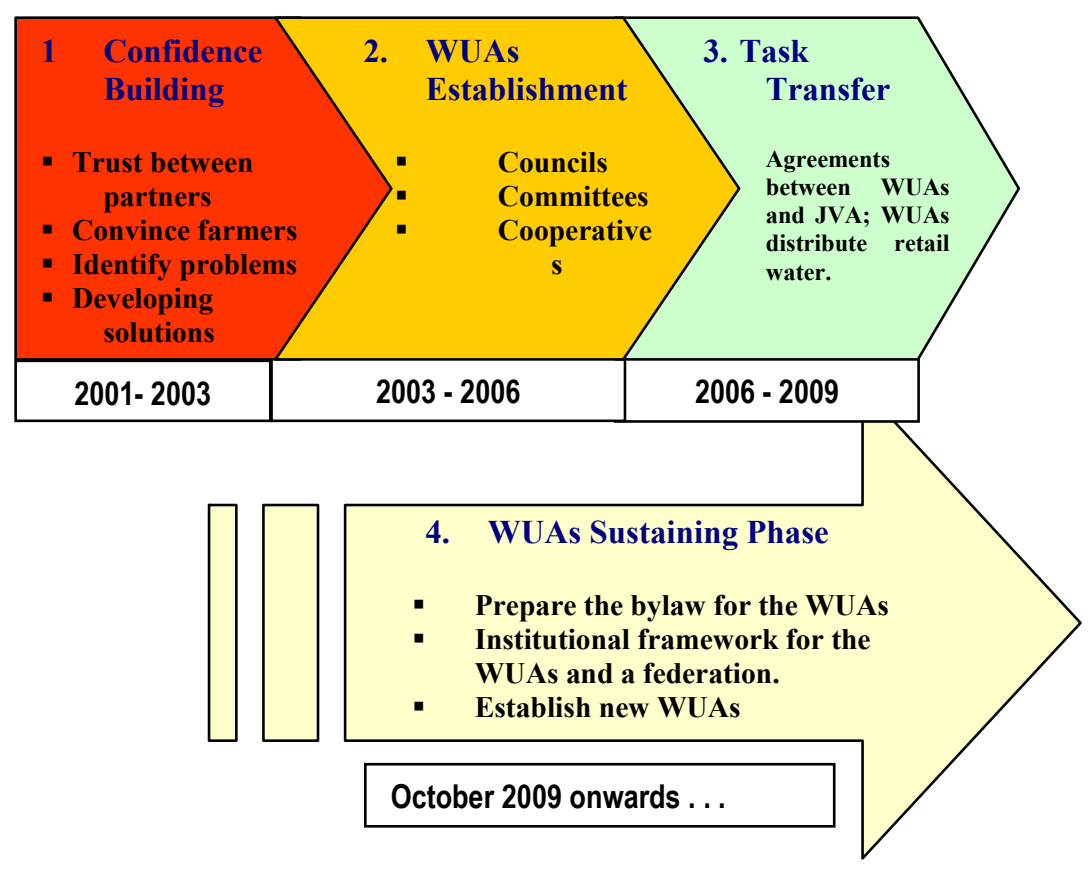

Figure 2: Complete project cycle.

taking into account the sophisticated technologies for irrigation water distribution of high pressure pumping and the associated maintenance, it became imperative to have a well organized form of farmers management groups i.e. the WUAs.

To make the change in managing water resources and to reach to a participatory approach leading to the formation of water users associations, a dedicated (open, transparent and flexible) process had to be in place. At the outset a comprehensive understanding of the local issues was targeted. This included understanding the local traditions, socio-economic aspects and the problems and difficulties facing the farmers. A social study was also done to understand the opportunities and constraints of farmers' participation.

Care was given to respond to the problems facing the farmers in a structured approach. Technical capacity needs were taken into account and thus facilitated the maintenance work to reclaim the water network. Awareness raising and human resources capacity building were also a major topic. A number of workshops were held in the communities to advance the level towards the sought better management of irrigation water via participation. The workshops included

- Farmers participation in irrigation management;

- JVA and water users groups communication workshops; and

- Joint JVA - farmers - water users groups project planning workshops.

To advance the knowledge and sharing experiences, technical field visits were implemented. These included visiting communities in the south of Jordan, where 
the participatory approach through water committees had been in place for a long time; and technical visits to Syria, Turkey and Egypt, where strong water users associations have been a successful practice.

When the concept gained the support of the farmers, forming the suitable shape of water associations in the pilot study area in the north, middle and south of the Jordan Valley was started. The WUAs took the following forms (1):

- Water councils and water: They are based on the traditional mechanism of problem solving. Water councils are recognized by JVA. Each council has $15-20$ elected farmers.

- Water user committees: they are also based on or similar to the traditional form of farmers' management that existed before the formation of JVA. A water users committee is a group of representatives of farmers elected by the farmers in a general assembly after several informal meetings. Although the committees have no legal status as such, they are recognized by JVA; normally a letter is issued by the JVA Secretary General in this respect.

- Water users' cooperatives: they are the type of associations that have a legal status. Cooperatives follow the Jordan Cooperative Corporation JCC (Law No. 18/1997). Cooperatives must have their internal statutes that specify the objectives, capital, membership procedures and financial and administrative issues. It should be noted that JCC was the only available facility to register the water associations. In January 2010, however, a dedicated bylaw to allow establishing WUAs under the water related authority was drafted. A bylaw for a WUAs federation is also being drafted.

\section{Results and discussion}

As a result of the surveys and meetings with the farmers, the identified key problems that were facing the farmers at the outset of introducing the approach were

- Unreliable supply of water both in quality and quantity due to lack of planning, stress on water, lack of proper management system, and lack of efficient maintenance;

- Lack of efficiency of some JVA water distribution staff and the support to farmers to meet their needs;

- Competition among farmers on water leading to bad practices like illegal connections and abstractions, thus affected trust among farmers;

- Competition and mistrust between the small farmers and the influential large farmers;

- Demand on water for other uses such as the tourism sector in the Jordan Valley (JV) that would also compromise the allocation for agriculture.

The results of the social study [1] revealed that

- There existed a potential (even though low) for farmers to accept each others; thus farmers had to be subjected to training and offered initial support to participate more actively. 
- The farmers had great demands and wishes from JVA to reclaim the situation and grant efficient water management. However, they also had the understanding that JVA had to undergo a reform and water users associations had to have a clear role in water management.

- The farmers were also aware of the urgency of having legal status for the water associations. They also were demanding for capacity building and incentives.

The change process adopted has been effective. It resulted in forming 9 water associations ( 6 committees, 3 councils, and 1 cooperative) by the first phase in 2003. Progressive work on the water associations and based on the success, more water associations were formed reaching to 21 associations by October 2009. Thus more than $75 \%$ of the irrigated areas in the Jordan Valley has become managed in cooperation with the WUAs. In March 2010, the water users associations operating under task transfer reached 11 .

\subsection{Challenges and difficulties faced}

Certainly handling historical disparity and mistrust accumulated through a number of years and making a positive change was not an easy task. The challenges and difficulties faced at the outset can be summarized as follows [3]:

- Mistrust and resistance of farmers to change due to previous negative experience with JVA. For example the farmers in the beginning had doubts about the intention of granting transfer of tasks; they thought that JVA would not do it.

- Severe shortage of water resources (in addition to the change in quality) and the diversion of much of the fresh water to Amman, the capital, for drinking purposes made the farmers believe that irrigation will always be a second if not third priority.

- Influence of large farmers; large farmers may have their connections to manipulate the system.

- Absence or lack of adequate legal frame for the farmers' participation in the irrigation management made the farmers feel insecure about the future of the WUAs and the operation of the task transfer.

- Worn out supply and distribution network coupled with much of illegal connections.

- Negative attitude of some junior water distribution staff of JVA who did not favor the change; they preferred continuing business as usual for their own benefits.

Difficulties were solved and challenges were overcome by opening endless dialogue and a track of openness and understanding between one and another. The mistrust was leaned first by meetings and opening a room for discussion, then the participation was developed further by sharing developing the concept and the planning process. The technical needs were responded to in a speedy way to furnish the farmers with some of their key immediate aspirations such as 
reclaiming some parts of the irrigation network, providing information on modern techniques in irrigation management and best practices in agriculture.

To demonstrate the positive features of cooperative participative work in agriculture, the technical field visits to Turkey, Egypt and Syria were beneficial. These did not only provide exposure to management of WUAs, but also technical know-how on advanced techniques in agriculture and a platform for the farmers to go over their era of individualism. Furthermore, the participation was fortified by the offering of JVA top management to brainstorm with the farmers and the WUAs the needs, strategies, and work plans for the future management of irrigation water. The farmers and JVA became thus full partners.

\subsection{Success factors and the achievements}

Based on previous reports and meetings with concerned persons, the factors for the success were

- The bottom - up approach was a key success factor; the ideas were extracted from the field i.e. from the farmers.

- The concerted ability and commitment to make a change among the dedicated farmers (WUAs) and the authority was also an important element. This was developed through the continuous dialogue among the stakeholders (farmers - GTZ project - JVA) and was backed by the presence of wise project undertakings and support. The dialogue followed by immediate implementation/action taking resulted in proving good intention, trust and confidence.

- Respecting the status of the new form of water management entities and recognizing the successful ones in appropriate times.

The successive propagation of the adoption of participative irrigation approach is a good indication of the acceptance of the process. Moreover, farmers' satisfaction reached high rates, today $95 \%$ of the farmers are well served with water while in the past only $5 \%$ were benefiting (4).

The approach resulted in direct savings of water resources. One WUA (Al Kafrien, in the middle of the valley) reduced the water released from the corresponding dam to the network from $12000 \mathrm{~m}^{3} /$ day to $6000 \mathrm{~m}^{3} /$ day. This was achieved only in 2 months after handing over the water distribution task to the WUA. This made the farmers able to withstand and manage their farms even with less amount of water in the dry seasons.

In some areas where the access to the farm irrigation assembly was not possible, the WUAs (such as in the north (Al-Mashare')) managed to secure access to almost all the farm units. This enabled better control of water flows and distribution. It reflected the cooperation of the farmers as well as the importance of having a good control by the WUA. The endeavor led to reaching fair and equal distribution of water and after all improved efficiency.

In fact the continuous engagement in participative irrigation management built up valuable experience and progressive mutual belief in the ability to change. Some WUAs were able to meet and go over challenges in remarkable times. The WUA of Al Kafrein gained success in very outstanding short time. 
After working as a water council, it formed a cooperative in November 2006, then the transfer of tasks was achieved in February 2009, although it was one of the areas that suffered very much of illegal water uses and almost completely damaged irrigation system.

The approach resulted in numerous socioeconomic and soft skills benefits; these were illustrated in improving income, democracy level, and team work. The communities reported that their farms productivity increased as the water became available in a systematic way; the plants were irrigated according to the set schedule. In case of trouble shooting in the system, the problem was reclaimed immediately and so the farmer did not miss the turn in irrigation. In addition, the availability of a reliable irrigation management encouraged farmers to expand their farms areas and some to invest in farming business. The approach was sort of contributing in rebuilding the trust in the agricultural sector in the valley.

The approach also resulted in raising the level of participation. An important aspect, however, was the level of democracy gained throughout. The farmers became responsibly democratic. The communication and management skills have also been improved.

On the other hand the approach improved the image of JVA. The support given by the JVA was also well appreciated. It was noted that the top management support was a key element for WUAs to succeed. The mode of work in a participative approach was like a partnership for one goal. The experience offered a room for JVA to reshuffle performance via the modified bylaw issued at the time of the inception of the project. JVA even documented receiving much less complains from the farmers on water allocation and distribution issues.

The bylaw for the security of the WUAs was a major achievement. Although recognition was granted by JVA for each of the performing WUAs, but establishing the suitable institutional and legal frame was also a necessity for the sustainability of the practice. The bylaw has been drafted and it is being processed by JVA. The bylaw has been prepared in an open consultative manner with the WUAs ensuring good governance. Responding to the needs of the farmers, the legal system for a federation to represent the WUAs at the policy level is being prepared for according to the plan (see Figure 2).

The fair distribution of water was a great achievement of this endeavor. By the formation of WUAs a social pressure was exerted that enabled stopping illegal practices leading to unfair water allocations. Influential farmers became treated like ordinary farmers in terms of the amount of water they should receive. Certainly this injected a form of equity, better comfort and satisfaction on the ordinary social level indicating good governance. This progress was documented via the number of penalties along the years that showed dramatic decrease. For example in one area the penalties decreased from 134 to 27 in the same year after taking over the responsibilities. That was indeed a good indicator of respect to rights and change in behavior by practicing water use ethics in the concerned community. 
The farmers and members of the communities highly valued the experience in participative water management. The most valuable aspect of this endeavor was improving the efficiency of irrigation water and the management of water resources. The second level was the improved relationship with JVA and the fair distribution of water. At the third level was the improved cooperative relationship among the farmers, gaining trust and confidence, and improving the maintenance works [4]. It should be noted that the WUAs became an important resort (or resource body) for the farmers, as they became favouring expressing their needs to the WUAs even if the farmers were not members of the WUA.

The participation was not limited or restricted to any form of social level or background. The coverage was comprehensive; participation was among small and large farmers, rich or poor and of mixed origins. Foe example farmers of large investments who had connections to international markets were also interested and active in the WUAs. Women role received respect in the participation. In some communities women role was well pronounced; women farmers were present in the WUA covering their areas. Thus ensured equal rights for women participation (in this case) in irrigation management. In fact in one WUA in the North that comprised 186 members, 13 members were women farmers $(7 \%)$.

The WUAs proved also good internal governance and learning process. Some WUAs leaders were happy to chair the association due to the sought prestige and societal position. However, when this was not accompanied by real actions taking and improving the performance, the members of the WUA were able to change the leader. This was a good confirmation that the participative approach was for the good of all.

The WUAs through this involvement managed to enhance their knowledge of hydraulic principles governing the secondary water distribution system. Thereafter they could jointly with JVA optimize water distribution schedules for acceptable working pressure in the pipelines and receive the responsibility of self-operation of their farm gates (formerly task of ditch riders). This largely led to an adjusted water distribution to farm water demand requirements. Thus ensured that equal rights are observed among the farm units [3].

It should finally be noted that the impact of the success made reached the highest levels in the set-up of water management; the recent Water Strategy (2008), issued by the Royal Water Committee, adopted the approach and called for intensifying it [5]. The government is now in full support of the participative irrigation management via WUAs.

It was learnt that the change shall be made in a step by step approach. This was illustrated in the different phases and activities undertaken. Through out the road from disparity to unity, many actions for breaking the ice, bridging the gaps, developing mutual trust and confidence were imperative. Such activities included general assemblies, groups work, brainstorming and planning sessions in addition to one on one meetings to handle problems and difficulties. All of these were found useful and effective. Then the facilitation of technical support was a vital tool to furnish the confirmation of reliability and good intentions of the initiative. The change from complete reliance with negative attitudes and 
perceptions to full task transfer formed a print of success for the cooperative work.

\section{Conclusions and recommendations}

Throughout the life of the project since 2001, many lessons were learnt and difficulties were overcome. It is thus important to preserve the experience gained and to build upon it; it is beneficial to use these lessons and approaches in solving obstacles in the further work in establishing participative irrigation either in Jordan and elsewhere. The experience gained here is really unique; it represented the formation of a participative irrigation management from a severely disrupted system and yet involving various social structures and levels.

The communities became ready to look for the future and to entrust the junior farmers and the coming generation that they have to work and operate through WUAs. The approach improved water efficiency and productivity, it also advanced equality and good governance.

The step by step approach was a key factor for the success. In steps the members of the WUAs developed ownership. The participative irrigation management links well with the traditional way the farmers - at least in this part of the world - used to adopt for years. It is based on equal rights and has a religious dimension as well. Therefore it is recommended to utilize this unique feature in further developments and replication of the approach.

It is recommended that future initiatives for participative irrigation make best use of the drivers of change (sustaining water for agriculture) determined by the society (beneficiary party) as was adopted in this project. In this way the results will be relevant and the positive impacts would be more significant.

\section{Acknowledgement}

The authors acknowledge the support of the German-Jordanian Programme "Management of Water Resources" managed by Deutsche Gesellschaft fuer Technische Zusammenarbeit (GTZ) GmbH and the Jordan Valley Authority.

\section{References}

[1] GTZ Water Resources Management for Irrigated Agriculture, second and final report of phase 1, June 2002-November 2003.

[2] Jordan Valley Development Law and it amendments in 2001, Jordan Valley Authority.

[3] Mutz, D. \& Hayek, B.O., Efficient water resource management in irrigated agriculture in the Jordan Valley and Highland areas, GTZ interim evaluation report, 2008.

[4] B. O. Hayek, The Story of Participative Irrigation Management in the Jordan Valley, GTZ, November 2009.

[5] Water Strategy, Ministry of Water and Irrigation, 2008. 